\title{
Delineation of Fractured Aquifer Using Numerical Analysis (Factor) of Resistivity Data in a Granite Terrain
}

\author{
Rolland Andrade \\ Central Water and Power Research Station, Ministry of Water Resources, Pune 411024, India \\ Correspondence should be addressed to Rolland Andrade; rollandandrade@gmail.com
}

Received 2 May 2014; Revised 27 September 2014; Accepted 28 September 2014; Published 14 October 2014

Academic Editor: Yun-tai Chen

Copyright (c) 2014 Rolland Andrade. This is an open access article distributed under the Creative Commons Attribution License, which permits unrestricted use, distribution, and reproduction in any medium, provided the original work is properly cited.

\begin{abstract}
In hard rock terrain, fractured aquifers comprise the major source of groundwater availability where the phreatic aquifer is desaturated. Identification of fracture zones in hard rock terrain and potential groundwater source delineation had been a perennial problem in hydrology. The purpose of this paper is to highlight the study over a small watershed area, in a granite terrain, wherein an attempt was made to delineate and map the fractured aquifer using numerical (factor) analysis of the conventional vertical electrical sounding data, which was obscure in curve matching technique. This numerical approach in concatenation with resistivity imaging or other techniques would prove to be an effective tool in groundwater exploration.
\end{abstract}

\section{Introduction}

The quest for water for all purposes in life has drifted from ordinary search for surface water to ground water through boreholes with the advent of technology. Rapid industrialization, population growth, agricultural related activities, and natural climatic imbalance have forced mankind into overexploitation of natural resources, of which groundwater is one of the vital commodities. Groundwater in lithological formations is generally identified by several physical parameters of the subsurface which are determined by geophysical methods such as electrical resistivity methods, seismic methods, magnetic methods, and gravity methods. By and large, vertical electrical sounding (VES) with mostly Schlumberger and Wenner configurations is conventionally practised in different parts of the world $[1,2]$ by geologists from Central Groundwater Board, Geological Survey of India, State Groundwater Division, Universities, and so forth. It is reported that the electrical resistivity method for groundwater exploration in a sedimentary environment has proven reliable [3]. Several investigation records have shown that the depth to aquifer differs from place to place depending on various factors like variational geothermal and geostructural occurrence $[4,5]$.

The resistivity investigations in hard rock regions by and large reflect in $\mathrm{A}, \mathrm{H}$, or HA type of sounding curves.
In hard rock terrains especially granites and charnockites, deciphering the actual depth to the aquifer zone using conventional resistivity curve matching technique is difficult. Hence, drilling of bore wells and tapping fractured aquifer at desired location and depth, based on data interpretation by conventional method, may not yield aquifer zones at interpreted depth. In this paper the basic resistivity (VES) data from granite terrain was subjected to a semiquantitative approach, namely, factor analysis, in order to eliminate the suppression effect from the overburden and to refine the depth to aquifers in a granite terrain. The hindrance in clarity to the fractured aquifer depth had compelled in examining the raw data of VES within a small area of $2 \mathrm{sq} . \mathrm{km}$. in a granite terrain of Nalgonda district, Andhra Pradesh, Indian subcontinent. The factor analysis showed good correlation with the actual aquifer depth drilled. This technique was adopted by geologists, hydrologists, and consultants in the field of groundwater exploration of different state and other groundwater divisions.

The geology of the study area under discussion mainly comprises pink feldspathic granite with different degree of weathering resulting in vertical and oblique joints and fractures. The soil thickness varies from $20 \mathrm{~cm}$ in the elevated part to a maximum of $4 \mathrm{~m}$ in valleys and plains. The soil is mostly loamy, sandy loam, and loamy sandy and is classified as red soils. The thickness of weathered granite residuum varies 
widely and ranges between 8 and $20 \mathrm{~m}$. Shallow, horizontal to inclined fractured and fissured granites occurred beneath the weathered zones extending up to $30-75 \mathrm{~m}$ below ground level. Major part of the watershed (central area) is undulating plain country with isolated residual hills, while the western side is occupied by north-south trending hill ranges. The topographic elevation varies from $730 \mathrm{~m}$ above mean sea level (AMSL) to $312 \mathrm{~m} \mathrm{AMSL}$, and the slope of the watershed is towards ESE. The entire watershed area can be classified into four important geomorphic units, namely, denudation hills, dissected pediment, valley fills, and pediplain. The prime source of groundwater in the watershed area occurs under both phreatic and semiconfined conditions in the weathered and fractured granites.

\section{Study Area}

The study area under discussion is located in semiarid climate zone of Indian subcontinent with average annual rainfall of $500 \mathrm{~mm}$. As mentioned earlier, the area is situated in Nalgonda district, Andhra Pradesh, lying between latitude 17.8 and $17.158 \mathrm{~N}$ and longitude 78.88 and $79.8 \mathrm{E}$. There are several irrigation and development projects implemented in the district to uplift and sustain the declining groundwater status. In general the groundwater abstraction is on the higher side with about 55556 bore wells and about 109380 dug wells existing in the district [6]. The study area comprising $\sim 2$ sq. km. is located at a distance of about $75 \mathrm{~km}$ East South East (ESE) of Hyderabad city, India. The agricultural sector in the study area mainly depends on groundwater resource for cultivation. The study area forms the part of Krishna river catchment and is characterized by rugged terrain with hills and plains [7]. The drainage pattern of the area is parallel to subparallel in the western part and subdendritic to dendritic in nature in the eastern part as seen in Figure 1.

The area under study is devoid of dependable and sustainable irrigation facility. Surface water irrigation facilities in the form of minor irrigation tanks locally termed as Cheruvu in the area are dry for the last 4-5 years due to continuous chronic drought condition in the area. Hence the agricultural sector is mainly dependent on groundwater for sustaining the basic need for cultivation, during pre-monsoon periods. Survey on well inventory in the study area revealed few tens of open wells and large number of dug-cum-bore and bore wells drilled up to the maximum depth of $80 \mathrm{~m}$. Yield test carried out for dug-cum-bore and bore wells was not prospective in more than $50 \%$ of the cases due to the occurrence of massive rocks and dry fracture zones. The study area has three bore wells (BW-1, BW-2, and BW-3) drilled $60 \mathrm{~m}, 55 \mathrm{~m}$, and $58 \mathrm{~m}$, respectively, trending NNW and SSE direction along the course of the rivulet, as shown in Figure 1.

\section{Materials and Methods}

Geophysical prospecting of groundwater refers to both surface and subsurface exploration. Geoelectric sounding (VES) survey using Schlumberger configuration was conducted in the study area, using resistivity meter of IGIS, Hyderabad
(India) make, with accessories. Schlumberger configuration was adopted to acquire deeper current penetration. Seven geoelectric soundings were carried out in the study area, along the alignment of the existing bore well. The bore wells BW-1 and BW-2 are separated by $55 \mathrm{~m}$ and BW-2 and BW-3 are $40 \mathrm{~m}$ apart. VES sites were chosen accordingly, covering almost equidistance from each bore well site. The Schlumberger electrode array employed in each VES was with the maximum half current electrode spacing $(\mathrm{AB} / 2)$ of $150 \mathrm{~m}$. The depth of current penetration using the Schlumberger electrode array is $1 / 3$ to $1 / 4$ of $\mathrm{AB} / 2[8,9]$, which was deemed sufficient and a depth of the order $38 \mathrm{~m}$ to $50 \mathrm{~m}$ was achieved. The axis of all the geoelectric soundings was aligned EW, perpendicular to the course of the rivulet cum groundwater flow direction in the area.

3.1. Resistivity Method. The resistance offered by the opposite faces of a unit cube of material to direct current is termed as electrical resistivity. Unit of resistivity in geophysical literature is connoted as the ohm.m. The resistance $(R)$ of the material having a resistivity $(\rho)$ over a length $(L)$ and surface area of current flow $(A)$ is represented by

$$
R=\rho \frac{L}{A} .
$$

The above relation is known as Ohm's law, which governs the resistivity of the geological formation. Resistivity is generally high under dry conditions and decreases with moisture or clayey material. Presence of water in voids, cracks, or fractures even in minor amounts eases the path for current passage and makes the geological formations relatively conductive.

3.2. Acquisition and Processing of Resistivity Data. The resistivity of the subsurface formation is measured using four electrodes, two metal bars for passing current into the ground (current electrodes) and two nonpolarizable porous pots for potential variation measurements (potential electrodes). The current of electrical intensity $(I)$ is introduced between current electrodes which can be identified as A and B. The potential difference produced as a result of current flow is measured with potential electrodes represented as $\mathrm{M}$ and $\mathrm{N}$. If $\Delta^{r}$ represent the potential difference, then the resistivity measurement is represented as

$$
K X \frac{\Delta^{r}}{I},
$$

where $K$ represents the geometric factor or configuration factor, which depends upon the electrode arrangements pertaining to a particular electrode configuration. Also the resistivity measured in the field is apparent, since the passage of current through geological formations is heterogeneous in nature. The acquired resistivity data of a vertical electrical sounding (VES) is plotted on a double log sheet, in order to accommodate both the spacing and apparent resistivity variations. 


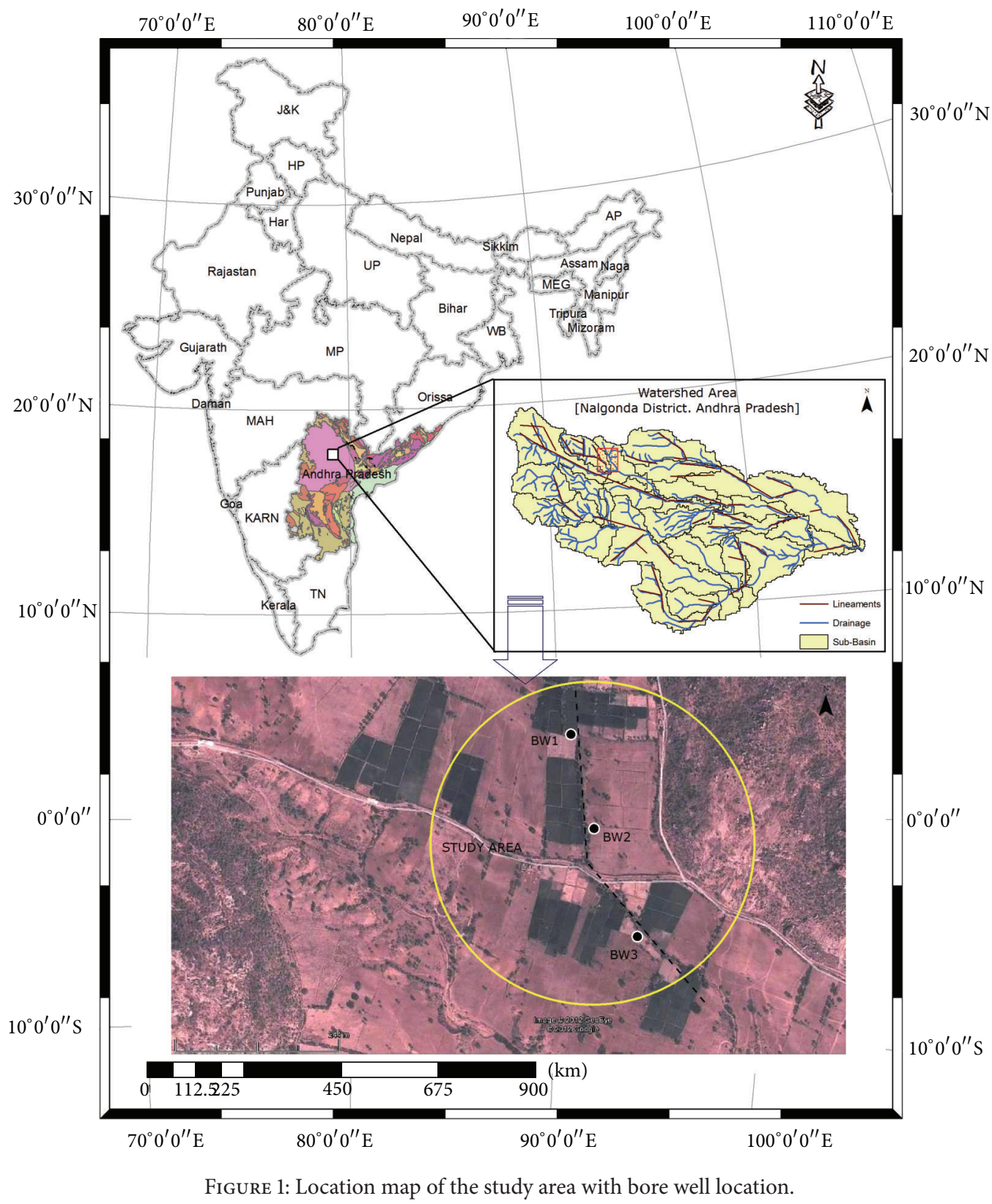

3.3. Interpretation of Resistivity Data. The data acquired from VES survey is subjected to quantitative interpretation so as to attain fairly good information about the subsurface (depthwise lithostratigraphic sequence) at the center of each VES. There are two methods in sounding interpretation, namely, (a) direct method and (b) indirect method. Of the two, the indirect method is discussed in this paper, as all the VES soundings are interpreted using this method. This method is based upon comparing the field curves with the sets of theoretical curves which are generated through computation processes. There are several catalogues of theoretical master curves calculated for a variety of layered lithological structure. The monograph by Bhattacharya and Patra [10] explains in detail about the principle and technique of interpretation by curve matching [11]. If the response of subsurface is of more layered nature, then the partial curve matching technique is adopted for interpretation.

During the computation, the derived geoelectric model from curve matching interpretation of the sounding data under processing is fed into computer based software like MS-RESIST, IPI2 Win Version 3.0.1, and so forth to generate best fit theoretical curve along with the RMS error. If the RMS error is lower than 2.5 (general acceptance factor) then the model derived from curve matching technique is usually accepted to be one of the suitable subsurface geoelectric layered sequences present at the investigated site. The final geoelectric layered sequences are transformed into hydrogeological conditions for further consideration in point of exploration and decision making. 
3.4. Calculation of "Factor" from Apparent Resistivity Data. Factor analysis is a statistical method used to describe the variability among observed and correlated variables in terms of a potentially lower number of unobserved variables called factors. The resistivity variation in lithology with increasing depth is more prominent in vertical electrical sounding compared to other investigation methods [12]. Processing and interpretation of VES data bring out numerous geoelectrical layers. In order to decipher and locate potential pay zones, the inference drawn from the layered parameters needs to be combined with local hydrological conditions. In granite terrain, mostly the existence of potential pay zones is in semiweathered or fractured granite. The apparent resistivity field data pertaining to such terrain hardly shows any significant change in the geoelectric trend which would be possibly interpreted as a separate geoelectric layer. Under such circumstances the apparent resistivity data is subjected to a calculation wherein the ratio of apparent resistivity of a particular separation of $\mathrm{AB} / 2$ to the cumulative apparent resistivities of earlier separations is calculated. The ratio is called "factor" as follows:

$$
F \rho_{a}^{10}=\frac{\rho_{a}^{10}}{\sum_{\rho_{a}^{1.5}}^{\rho_{0}^{8.0}}},
$$

where $1.5,8$, and 10 indicate the $\mathrm{AB} / 2$ positions.

The results are generally decimal followed by numerical values and two consecutive values pertaining to respective depths will be the same if there is a fracture at that depth. In the above manner, the factor for all the current electrode separations observed while doing VES is calculated. The factor versus $\mathrm{AB} / 2$ on a double log scale is then plotted to identify flat segments at places which represents probable fracture zones/pay zone.

\section{Results and Discussion}

The bore wells in the study area as mentioned were logged manually, based on the lithological samples collected at the time of drilling and also the information recorded in the driller's dairy. Drilling of BW-1 had encountered a fractured aquifer (pay zone) at a depth of 48-52 $\mathrm{m}$ with a yield of 25,000 litres/hour. Similarly drilling at BW-2 had encountered two fracture zones at 8-12 $\mathrm{m}$ and $43-47 \mathrm{~m}$. The latter happened to be the aquifer zone with a yield of 20,000 litres/hour. In the same continuity the BW-3 had encountered the fractured aquifer at $38-44 \mathrm{~m}$ with a yield of 16,000 litres/hour. A lithological section was attempted for the drilled bore wells with respect to mean sea level to depict the depth to the aquifer.

Further to geophysically trace the depth to the fractured aquifer at each drilled bore well location, VES was carried out. Three vertical electrical soundings, namely, 1, 4, and 6, were carried out near BW-1, BW-2, and BW-3, with $\mathrm{AB} / 2$ separation $100 \mathrm{~m}, 150 \mathrm{~m}$, and $130 \mathrm{~m}$, respectively, along EW orientation. Interpretation of the apparent resistivity plot using IPI2Win Version 3.0.1 for the three VES was carried out, but the results did not show any significant variation or change in resistivity at depths as mentioned by the driller. The sounding data was then subjected for factor calculation; the results are shown in Table 1 . The results revealed presence of fracture zones at different depths.

The apparent resistivity and its corresponding factor plot for the three VES are attempted on a double log scale as shown in Figure 2. The flat section in the factor plots highlighted in red boxes, corresponding to respective $A B / 2$ separation, indicates the presence of fractured granite. The factor analysis of VES-1 showed a flat segment between current electrode separations of $\mathrm{AB} / 2$ : 50 and 55 . The $\mathrm{BW}-1$ drilled was up to $60 \mathrm{~m}$ and the aquifer zone encountered during drilling was at 48 to $52 \mathrm{~m}$. Hence the error limit between the factor calculation and actual aquifer depth is around 5\%.

Similar to VES-1, factor analysis for VES-4 and VES-6 also showed flat segment (presence of fracture zone) between 40 to $45 \mathrm{~m}$ and 35 to $40 \mathrm{~m}$, respectively. Apart from these, there are a couple of more fractures deciphered in the factor calculation but at deeper levels. The drilled depths of the bore wells were restricted to $50 \mathrm{~m}$ to $55 \mathrm{~m}$; hence the other deeper fractures deciphered through factor analysis are not considered in discussion. The BW-2 and BW-3 had encountered aquifer zone during drilling at 43-47 $\mathrm{m}$ and 38$44 \mathrm{~m}$, respectively. Hence the error limit between the factor calculation and actual aquifer depth is around 5\% for BW-2 and $8 \%$ for BW-3, respectively.

Factor calculation was able to decipher fractured aquifer zones in the drilled bore well sites which were obscure in two/multilayer curve matching technique, and also the zones identified were at different depths. Based on these observations, intermittent distances between the bore wells were investigated to map the extent and continuation of the fractured aquifer zone. Electrical resistivity survey VES-2, VES-3, VES-5, and VES7 with AB/2 separation $150 \mathrm{~m}, 110 \mathrm{~m}$, $130 \mathrm{~m}$, and $130 \mathrm{~m}$, respectively, along EW direction parallel to the previous VES orientation was carried out. In concurrence with the interpretation of the apparent resistivity plot of VES1 , VES-4, and VES- 6 the electrical soundings VES-2, VES3, VES-5, and VES-7 also showed no significant variation or change in resistivity pertaining to the depths encountered at the time of drilling.

Similar to the previous soundings, factor calculation was attempted for the soundings VES- VES-2, VES-3, VES-5, and VES-7. As reported in the earlier factor calculation for VES1 , VES-4, and VES-6, here again similar flat segments were observed at depths 50 to $55 \mathrm{~m}, 35$ to $40 \mathrm{~m}, 40$ to $45 \mathrm{~m}$, and 30 to $35 \mathrm{~m}$, respectively, corresponding to their respective $\mathrm{AB} / 2$ separation indicating the presence of fractured granite aquifer. Based on the local geology, drilling information and factor calculation, a lithological section was attempted to map the aquifer zone as shown in Figure 3. The change in depth to the fractured zone (aquifer) between VES-2 and VES-3, approximately $10 \mathrm{~m}$ from BW-1 (VES-1), was due to the presence of a fault. Satellite imagery analysis and geomorphological investigation revealed that a fault extending NW-SE passes through the study area as shown in the inset in Figure 3. Later a 2D resistivity imaging was carried out in the N-S orientation, which revealed the presence of the fault in the above described orientation. Probably this might 


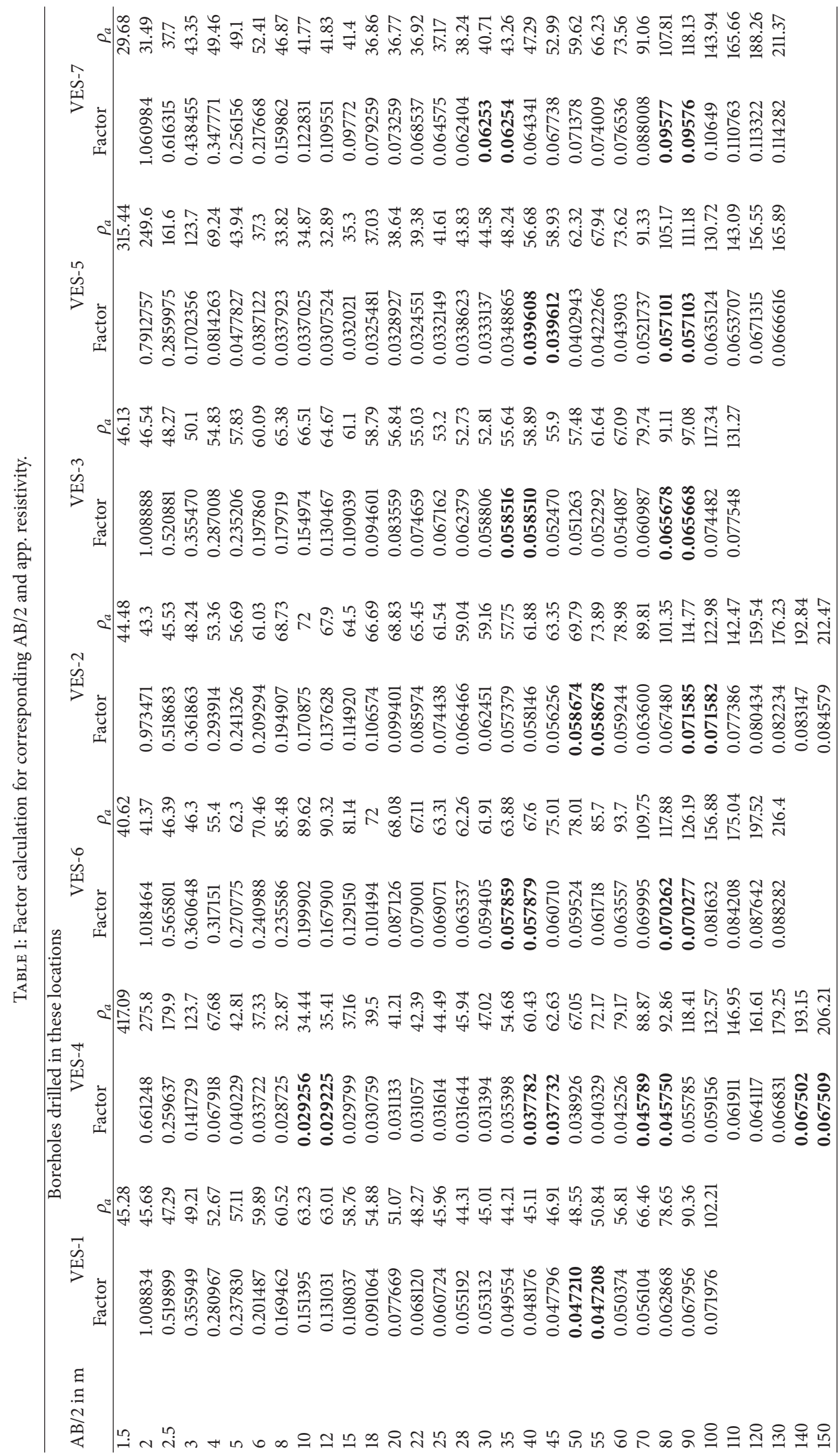



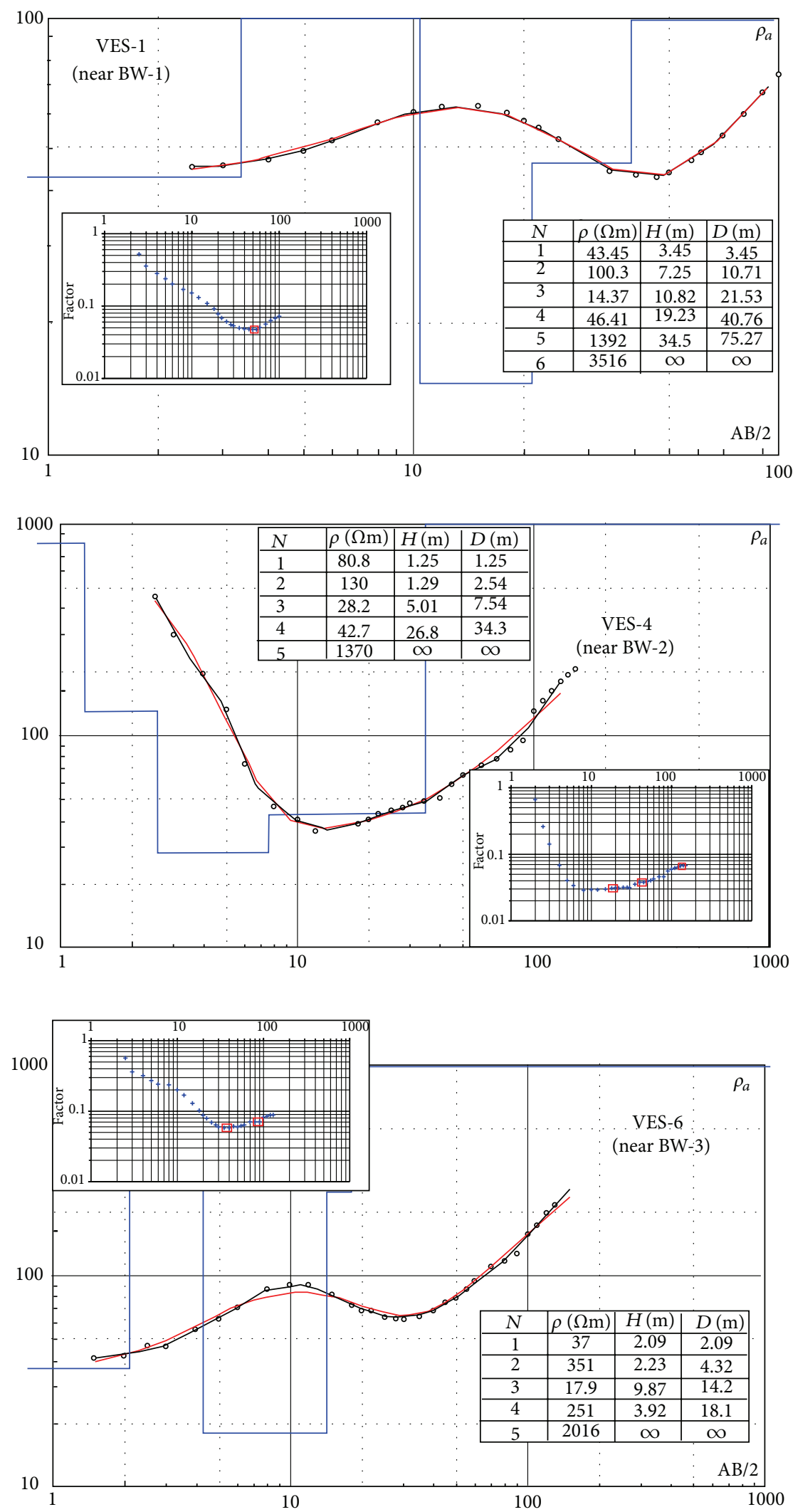

FIgURe 2: Apparent resistivity and factor plot for the VES. 

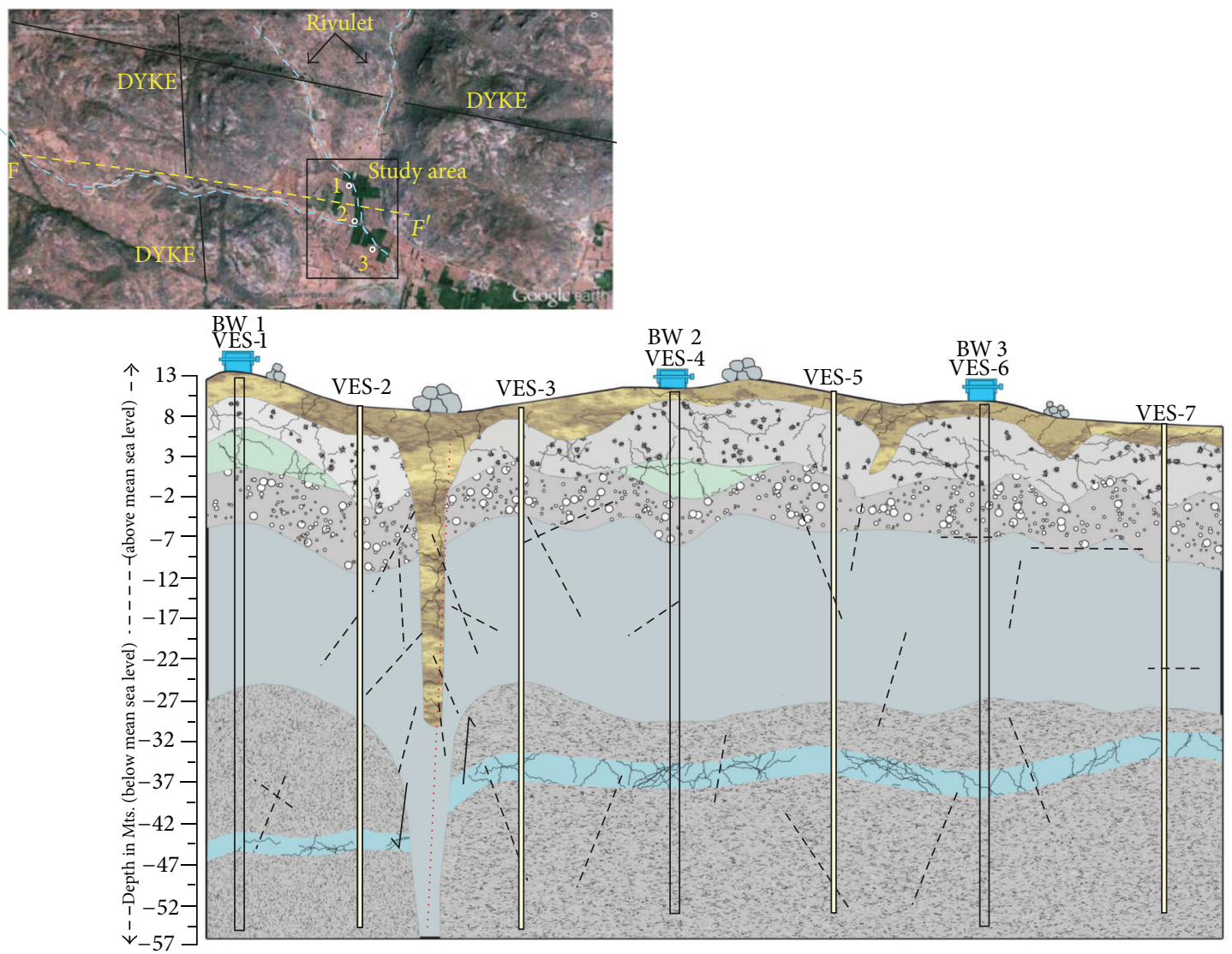

Lithology index
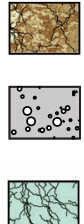

Fractured granite (dry)

Highly weathered granite
Top soil with Kankar (saprolite)

Weathered and fractured granite

FIGURE 3: Lithological cross section based on factor calculation. be one of the causes that the well yield drastically reduced from $\mathrm{BW}-1$ to $\mathrm{BW}-3$.

\section{Conclusion}

One of the limitations in two-layer curve matching technique of VES data is to identify deep seated fracture zones in hard rock terrain. The overburden thickness cumulatively adds to the effect of the underlying lithological layers, hence suppressing the effect of independent layer pertaining to respective depth. The practical utility of factor calculation of VES data is to minimise the effect of overburden thickness to a greater extent, which in turn helps in detecting and mapping the spatial extent of hidden fractured zones. Resistivity sounding is widely practiced by several government and autonomous agencies in the field of groundwater exploration in different provinces of the world. This technique of factor analysis can be adopted with better understanding of local hydrogeology, geomorphology, and so forth and can be extended for groundwater exploration in different geological terrain where surface water for drinking and/or agricultural practice is scarce.

\section{Conflict of Interests}

The author declares that there is no conflict of interests regarding the publication of this paper.

\section{Acknowledgments}

The author is thankful to Dr. D. Muralidharan (Retd., Scientist, NGRI) for his guidance and constant support 
during the entire study and also grateful to fellow colleagues of Groundwater Replenishment Division, NGRI, for their support in field investigation. The author extends gratitude to Director of the Central Water \& Power Research Station (CWPRS), for promoting the publication of this work.

\section{References}

[1] S. Ndlovu, "Using low cost geophysical methods to locate high yielding groundwater aquifers in the granite rock region of Matabeleland south province of Zimbabwe-a case of gwatemba area," Journal of Sustainable Development in Africa, vol. 13, no. 6, 2011.

[2] S. Chandra, D. Kumar, S. Ahmed, J. Perrin, and B. Dewandel, "Contribution of geophysical methods in exploration and assessment of groundwater in hard rock aquifers," in Proceedings of the 3rd International Conference on Water Resources and Arid Environments and the 1st Arab Water Forum, 2008.

[3] E. A. Emenike, "Geophysical exploration for ground water in a sedimentary environment," Global Journal of Pure and Applied Sciences, vol. 7, no. 1, pp. 97-102, 2001.

[4] A. S. Ekine and S. Osobonye, "Surface Geo-electric sounding for the determination of Aquifer characteristics in parts of Bonny Local Government Area of Rivers State," Nigerian Journal of Physics, vol. 85, pp. 93-97, 1996.

[5] E. Okwueze, "Preliminary findings of the groundwater resource potentials from a regional geo-electric survey of the Obudu basement area," Nigeria Global Journal of Pure and Applied sciences, vol. 2, no. 2, pp. 201-211, 1996.

[6] M. K. Rafiuddin, "Ground water information Nalgonda district, Andhra Pradesh," CGWB Report, 2007.

[7] R. Andrade and D. Muralidharan, "The influence of lithostratification on the infiltrating water front in a granite terrain," Hydrological Sciences Journal, vol. 56, no. 5, pp. 907-915, 2011.

[8] J. Bernard, "Short note on depth of investigation of electrical methods," http://www.iris-instruments.com/.

[9] A. Roy and A. Apparao, "Depth of investigation in direct current methods," Geophysics, vol. 36, no. 5, pp. 943-959, 1971.

[10] P. K. Bhattacharya and H. P. Patra, Direct Current Geo-Electric Sounding-Principles and Interpretation, Elsevier, Amsterdam, The Netherlands, 1968.

[11] E. Orellana and H. M. Mooney, Master Tables and Curves for Vertical Electrical Sounding over Layered Structures, Interciencia, Madrid, Spain, 1966.

[12] D. Muralidharan, "A semi-quantitative approach to detect aquifers in hard rocks from apparent resistivity data," Journal Geological Society of India, vol. 47, no. 2, pp. 237-242, 1996. 

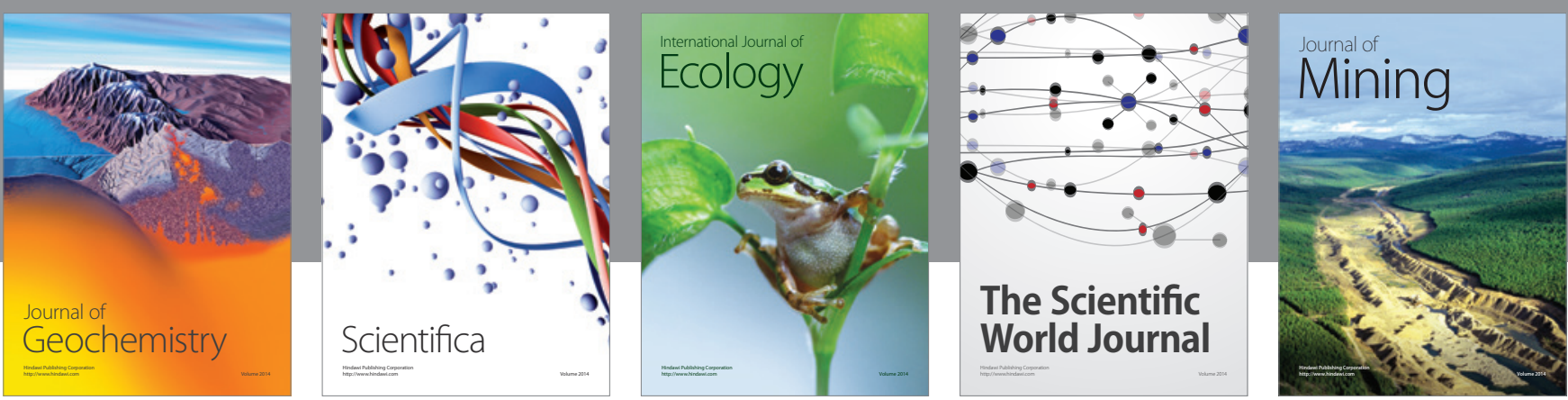

The Scientific World Journal
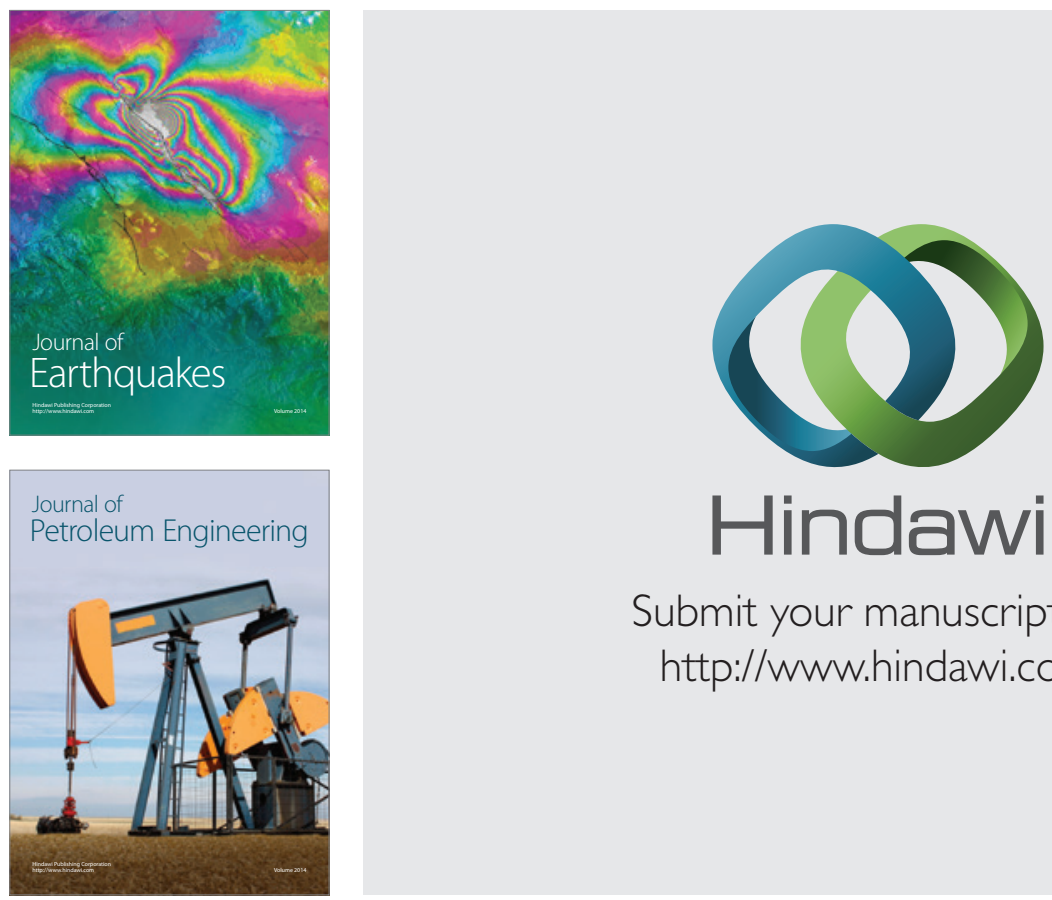

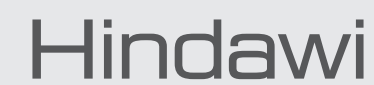

Submit your manuscripts at

http://www.hindawi.com
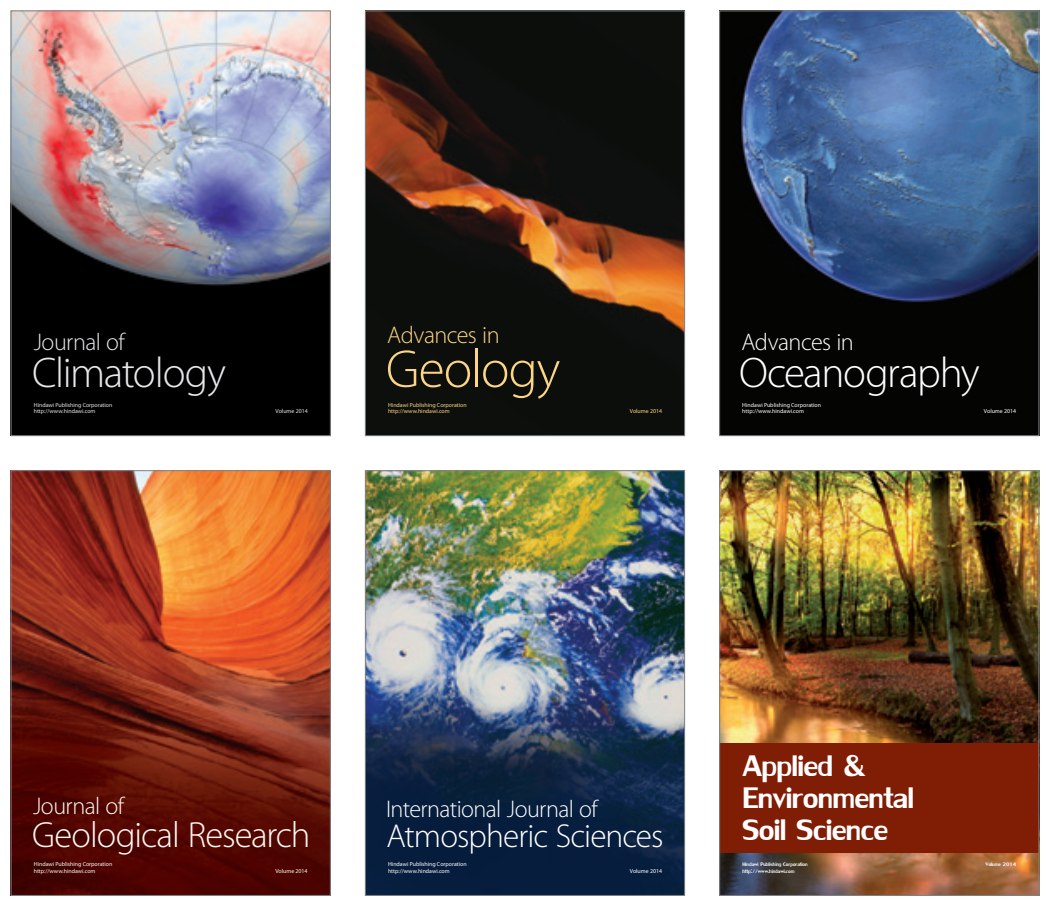
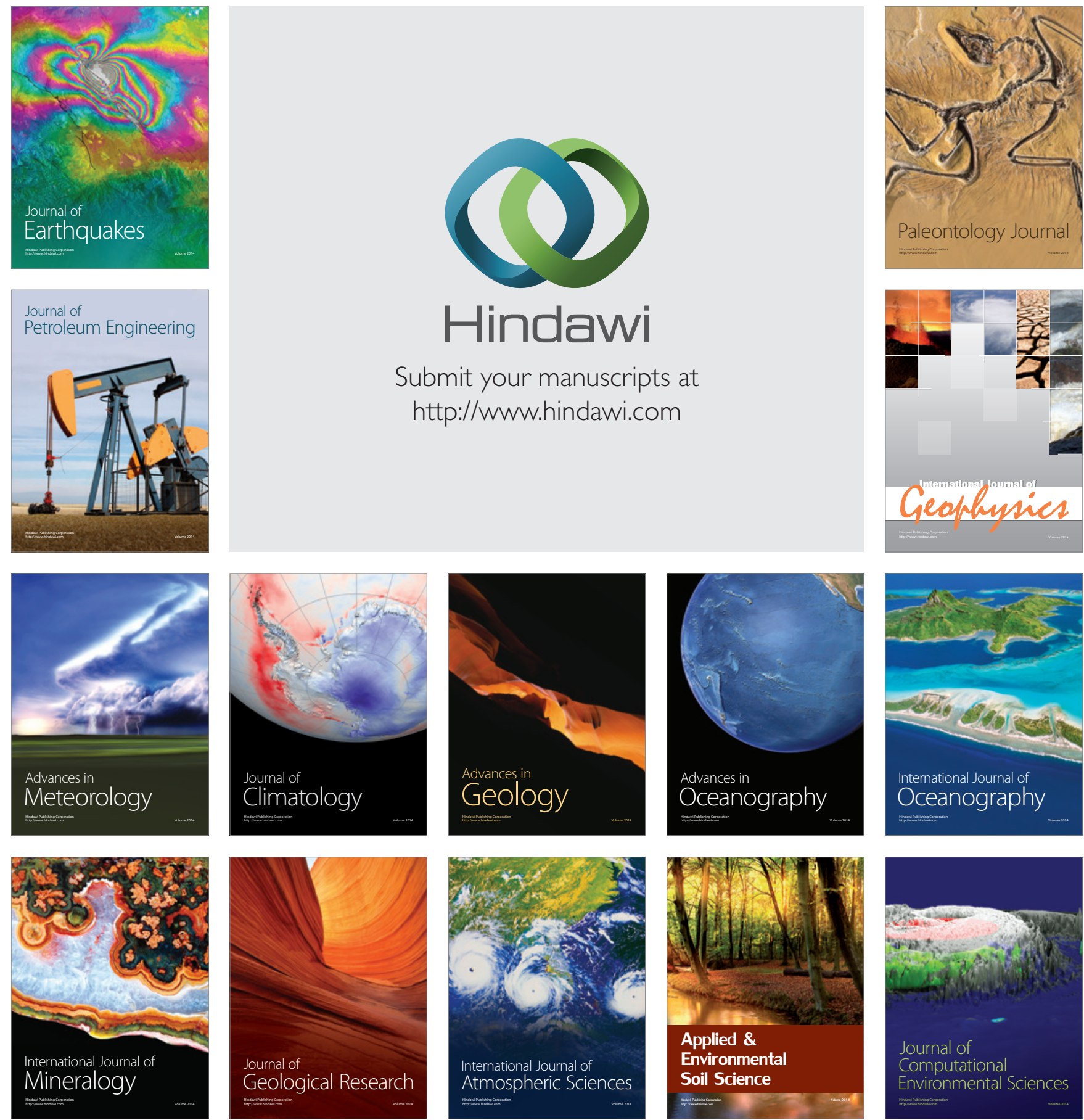